\title{
The Degradation Effects to Hand Made Composite Materials by Using Acids
}

\author{
MIHAI ALIN POP ${ }^{1}$, VIRGIL GEAMAN ${ }^{1}$, IRINEL RADOMIR ${ }^{2}$, TIBOR BED0 ${ }^{1}$, IOAN MILOSAN ${ }^{1}$, SEBASTIAN MARIAN ZAHARIA $^{3}$, \\ BOGDAN FLOREA*, AUGUSTIN SEMENESCU ${ }^{4}$, OANA ROXANA CHIVU 5 \\ ${ }^{1}$ Transilvania University of Brasov, Department of Materials Science, 29 Eroilor Av., 500036, Brasov, Romania \\ ${ }^{2}$ Transilvania University of Brasov, Department of Mathematics and Informatics, 29 Eroilor Av., 500036, Brasov, Romania \\ ${ }^{3}$ Transilvania University of Brasov, Department of Manufacturing Engineering, 29 Eroilor Av., 500036, Brasov, Romania \\ ${ }^{4}$ University Politehnica of Bucharest, Faculty of Material Science and Engineering, 313 Splaiul Independentei, 060021, Bucharest, \\ Romania \\ ${ }^{5}$ University Politehnica of Bucharest, Faculty of Engineering and Management of Technological Systems, 313 Splaiul Independentei, \\ 060021, Bucharest, Romania
}

In the paper, are studied the effects of three acids (sulfuric, nitric and hydrochloric) in concentrations of $10 \%$ and $20 \%$ on the composite materials (type resins reinforced with fiberglass). These composite materials are obtained manually and lends itself to getting various containers (for water for example), but can be obtained containers for temporary storage of acids. Certain composite materials with various combinations of fiberglass with a precise number of layers can be used for temporary storage of acids as a result of experimental research made in these paper are also given.

Keywords: Composite materials, corrosion, acids, degradation

The development of light materials with height mechanical properties in the modern industries is one of the most critical issues. The studies of composite materials presents a particular interest due to their relative low weight per volume unit compared to the conventional materials like: high wearing and corrosion resistance, high mechanical characteristics reported to the wall thickness [1-3].

Fiber-reinforced polymer composites have been used in structural applications in the last years because of their good characteristics and light weight at low cost. The automotive industry and not only, has adopted these materials in new designing of lightweight vehicles or other applications.

The properties: physical, chemical, magnetically, electrical and mechanical are influenced by the compatibility between the base material (resin) with the reinforcing filler and the arrangement of components [4$6]$.

The composite material based on resin type reinforced with fiberglass (Stratimat and Tissue) with different specific weights, obtained manually, are suitable for manufacturing of goods and usual objects, or with special destinations as: the hulls of boats, vessels for storing various solutions, etc.

From the wide range of resins and existing inserts to obtain composite materials only a small amount of them have been investigated and studied.

Nowadays there is a tendency to reduce consumption of classical materials, to improve technologies, to simplify and reduce the production time. The new material types like resin reinforced with fibreglass are the future trend in industry and manufacturing products [7].

In order to design a specific composite material, the based architecture for the previous mentioned engineering applications, to withstand different environmental conditions, a good behavior and good characteristics are desired [8].
Following these objectives, the herein paper aims to present an experimental based comparison on several designs of glass fiber reinforced polymer composites with the aim of sizing the differences among their material property.

\section{Experimental part}

Materials and methods

The materials used and how to obtain these composites

In the study of this research, the authors have used for experiments, the following materials:

Resins:

- Nestrapol 96

Cobalt accelerator 6507

Methyl - ethyl - cetone peroxide 50\%

Hardener: D 605

Fibre glass:

- Stratimat with specific weight 300,450 and $600 \mathrm{~g} / \mathrm{m}^{2}$;

- Tissue with specific weight 300 and $500 \mathrm{~g} / \mathrm{m}^{2}$

The notations when using reinforcement materials are: tissue (NT1, NT2 ... etc.), stratimat (NS1, NS2 ... etc.) and for mixtures of tissue and stratimat (NTS1, NTS2 ... etc.);

These materials have been used to manufacture plates. The process of obtaining these composite plates was as follows:

- preparing the patterns ( with elevated walls) for making the plates; applying the removing wax in order to prevent the resin to stick/adhere to the walls of the pattern; drying and polishing the contact surfaces between the pattern and resin;

- preparing and cutting the fibre glass to the patterns dimensions;

- applying resin layers successively by brushing; after applying each layer - a tissue fibre glass sheet was placed by brushing. The process was repeated until the desired number of layers was reached.

\footnotetext{
*email: florea_b2004@yahoo.com; Phone: 0724296800
} 
Table 1

THE COMPOSITION OF OBTAINED AND EXPERIMENTED COMPOSITE MATERIALS

\begin{tabular}{|c|c|c|c|c|c|}
\hline \multicolumn{6}{|c|}{ Composite materials obtained } \\
\hline $\begin{array}{l}\text { No. } \\
\text { Crt }\end{array}$ & Symbolization & Resin & Fiberglass insertion & $\begin{array}{c}\text { Number of } \\
\text { insertion layers }\end{array}$ & $\begin{array}{c}\text { Specific weight of the } \\
\text { insertion } \\
{\left[\mathrm{g} / \mathrm{m}^{2}\right]}\end{array}$ \\
\hline 1. & N1-A & \multirow{25}{*}{ Nestrapol 96} & Without & - & - \\
\hline 2. & N1-B & & Without & - - & -.--- \\
\hline 3. & NS1 & & Stratimat & 3 & 300 \\
\hline 4. & NS2 & & Stratimat & 5 & 300 \\
\hline 5. & NS3 & & Stratimat & 7 & 300 \\
\hline 6. & NT1 & & Tissue & 3 & 300 \\
\hline 7. & NT2 & & Tissue & 5 & 300 \\
\hline 8. & NT3 & & Tissue & 7 & 300 \\
\hline 9. & NTS1 & & Stratimat + Tissue & $2+1$ & $300+300$ \\
\hline 10. & NTS2 & & Stratimat + Tissue & $1+2$ & $300+300$ \\
\hline 11. & NTS3 & & Stratimat + Tissue & $3+2$ & $300+300$ \\
\hline 12. & NTS4 & & Stratimat + Tissue & $2+3$ & $300+300$ \\
\hline 13. & NS4 & & Stratimat & 3 & 450 \\
\hline 14. & NS5 & & Stratimat & 5 & 450 \\
\hline 15. & NS6 & & Stratimat & 7 & 450 \\
\hline 16. & NT4 & & Tissue & 3 & 500 \\
\hline 17. & NT5 & & Tissue & 5 & 500 \\
\hline 18. & NT6 & & Tissue & 7 & 500 \\
\hline 19. & NTS5 & & Stratimat + Tissue & $2+1$ & $450+500$ \\
\hline 20. & NTS6 & & Stratimat + Tissue & $1+2$ & $450+500$ \\
\hline 21. & NTS7 & & Stratimat + Tissue & $3+2$ & $450+500$ \\
\hline 22. & NTS8 & & Stratimat + Tissue & $2+3$ & $450+500$ \\
\hline 23. & NS7 & & Stratimat & 3 & 600 \\
\hline 24. & NS8 & & Stratimat & 5 & 600 \\
\hline 25. & NS9 & & Stratimat & 7 & 600 \\
\hline
\end{tabular}

The following types of plates were produced with different compositions are given in table 1.

The behavior of composite materials in different solutions Given the opportunity to use these composite materials for various purposes (getting pots with various shapes, various containers for acids storage for a short or long time) the specimens cut from the sheets obtained were tested under the following conditions:

-the behavior in sulfuric acid $10 \%$,

-the behavior in sulfuric acid $20 \%$,

-the behavior in nitric acid 10\%,

-the behavior in nitric acid $20 \%$,

-the behavior in hydrochloride acid $10 \%$,

-the behavior in hydrochloride acid $20 \%$,

At first, the edges of the specimens were isolated against corrosive environment, because of the glass fiber capillarity was recorded an absorbtion of solution in the specimen mass.

The edges isolation was made with resin without fiber glass. This extra step requires additional time waiting (drying and curring) of about 7 days.

The mass variation of samples was determined by the difference between the mass of the sample before the experiment and after experiment.

The corrosion rate and the density can be calculated according to the relations (1) and (2) and are compared with scale of conventional corrosion resistance $[1,11]$.

$$
\mathrm{V}_{\mathrm{c}}=\mathrm{h} \frac{m_{c}}{\rho} ;[\mathrm{mm} / \text { year }]
$$

where:

$\mathrm{h}=$ number of working hours in a year;

$\mathrm{m}_{\mathrm{c}}=$ sample mass lost $\left[\mathrm{g} / \mathrm{m}^{2} \mathrm{~h}\right]$; 434
The density of the composite material is:

$$
\rho_{\mathrm{c}}=\rho_{\mathrm{M}}\left(1-\mathrm{v}_{\mathrm{f}}\right)+\rho_{\mathrm{f}} \mathrm{v}_{\mathrm{f}} ;
$$

where:

$$
\rho_{\mathrm{M}}=\text { resin density }=1210\left[\mathrm{~kg} / \mathrm{m}^{3}\right] \text {; }
$$

$\rho_{\mathrm{f}}=$ fiberglass density $=2540\left[\mathrm{~kg} / \mathrm{m}^{3}\right]$

$\mathrm{V}_{\mathrm{f}}=$ fiberglass proportion $=0.30$

For each experiment, the samples were cut and a layer of resin has been applied on the cutted edges, in order to avoid the direct contact of fibers with the solutions, which could lead to solutions absorption into the mass of the composites, due to capillarity of the glass fibers $[9,10]$.

$A$ resin layer has been applyed on the edges of the samples by brushing, according to manufacturer's specifications, regarding the drying and polymerization period ( 7 days under laboratory conditions).

The same type of resin was used for edges isolating as in the composites process manufacturing.

A PROXXON TYP FKS/E equipment (fig. 1) has been used for samples cutting.

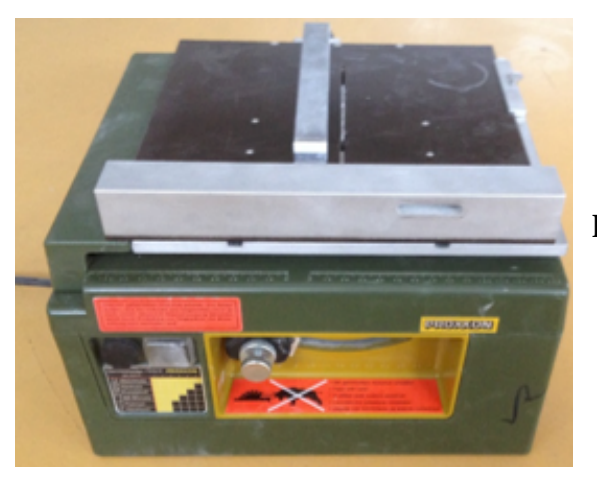

Fig. 1 PROXXON TYP FKS/E device 
The area of the tested samples was $50 \times 50 \mathrm{~mm}$. As the composites were manufactured a variation in the thickness of the samples has been observed (between 1.7 and 11.8 $\mathrm{mm}$ ).

Plates thickness is directly proportional to the number of layers of insertion and their specific weight.

Note. Depending on operator training and experience can get uniform plate thickness.

Each sample was weighted before each experiment and after at: 72, 144, 216, 288, 360 hours and respectively at 7 days of immersion in different solutions.

A Digital Scale equipment with $0.01 \mathrm{~g}$ precision (fig. 2) has been used for samples weighting.

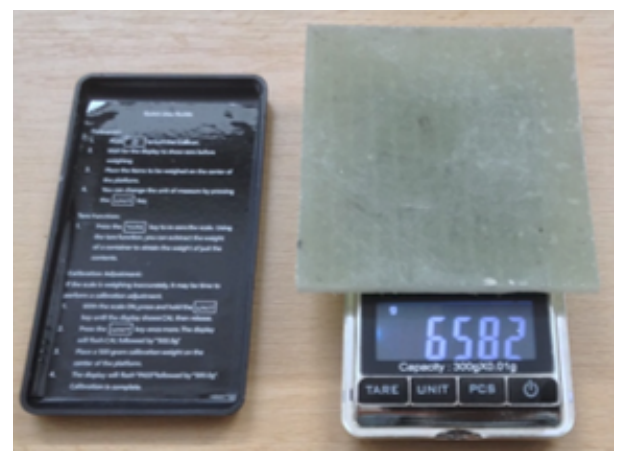

Fig. 2 Digital scale device

The temperature of acidic solutions was uniform and constant (laboratory conditions). Before each measurement samples were washed and wiped.

\section{Results and discussions}

The behavior of the composite materials in sulfuric acid $10 \%$,

The experimental results are summarized in the diagram presented in figure 3 .

\section{Observation:}

- From composite materials studied twelve of them it fits in group of perfectly stable material' and have the stability coefficient 1 , six materials fits in group of very little resistance and have the stability coefficient 8 and "non resistant" with the stability coefficient 10 fits three materials.

- After the experiment, the samples mass increased in the case of six materials. The mass increase was caused by degradation of resin by the acid and fiberglass came into contact with the acid solution and was soaked.

The behavior of the composite materials in sulfuric acid $20 \%$,

The experimental results are summarized in the diagram presented in figure 4.

\section{Observation:}

From composite materials studied six of them it fits in group of perfectly stable material and have the stability coefficient 1, nine materials fits in group of very little resistance and have the stability coefficient 8 and 9 , and non resistant with the stability coefficient 10 fits five materials.

After the experiment, the samples mass increased in the case of five materials. The mass increase was caused by degradation of resin by the acid and fiberglass came into contact with the acid solution and was soaked.

The behavior of the composite materials in nitric acid 10\%,

The experimental results are summarized in the diagram presented in figure 5 .
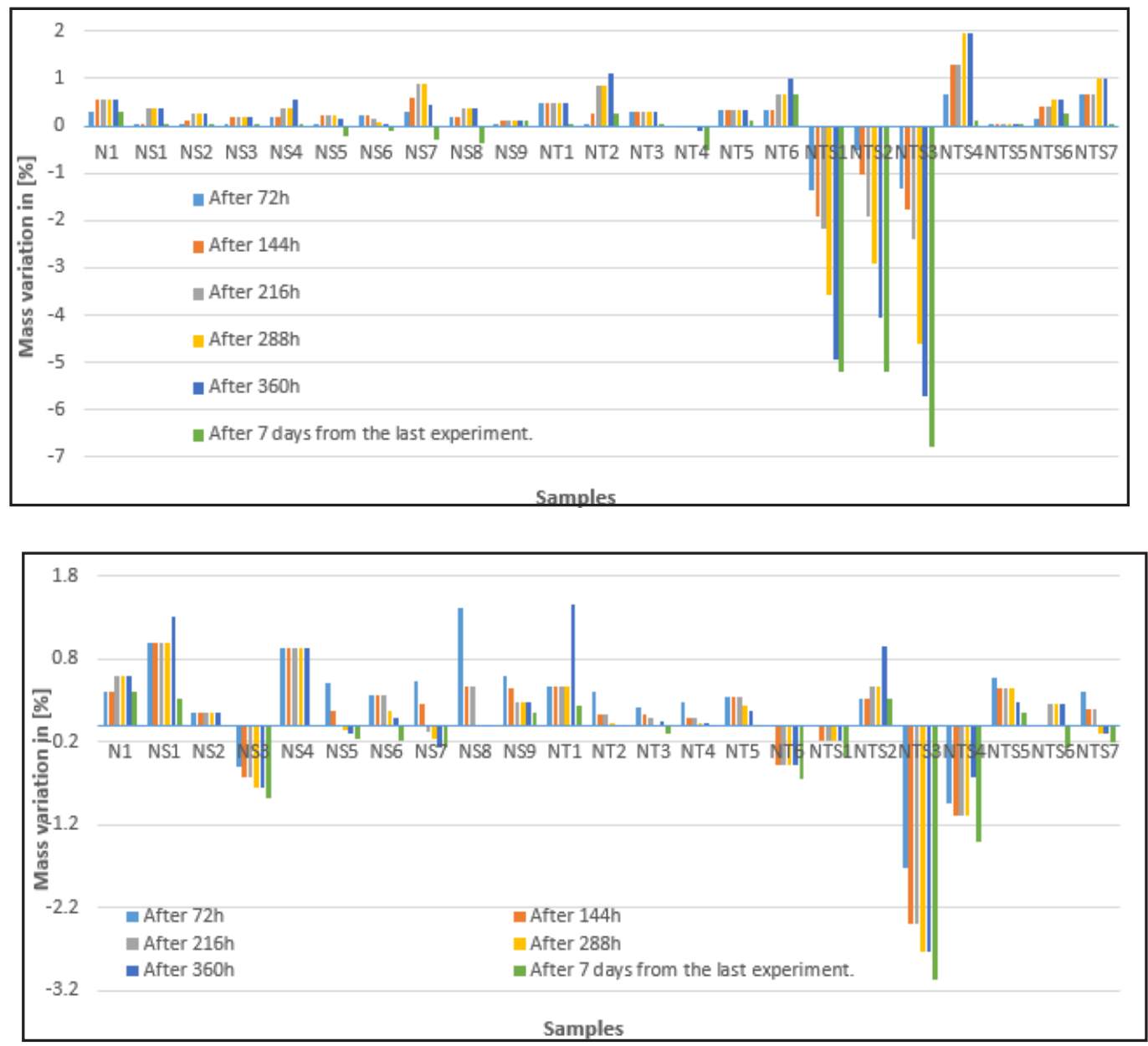

Fig. 3. The variation of mass specimens calculated in [\%] in sulfuric acid $10 \%$

Fig. 4. The variation of mass specimens calculated in [\%] in sulfuric acid $20 \%$ 


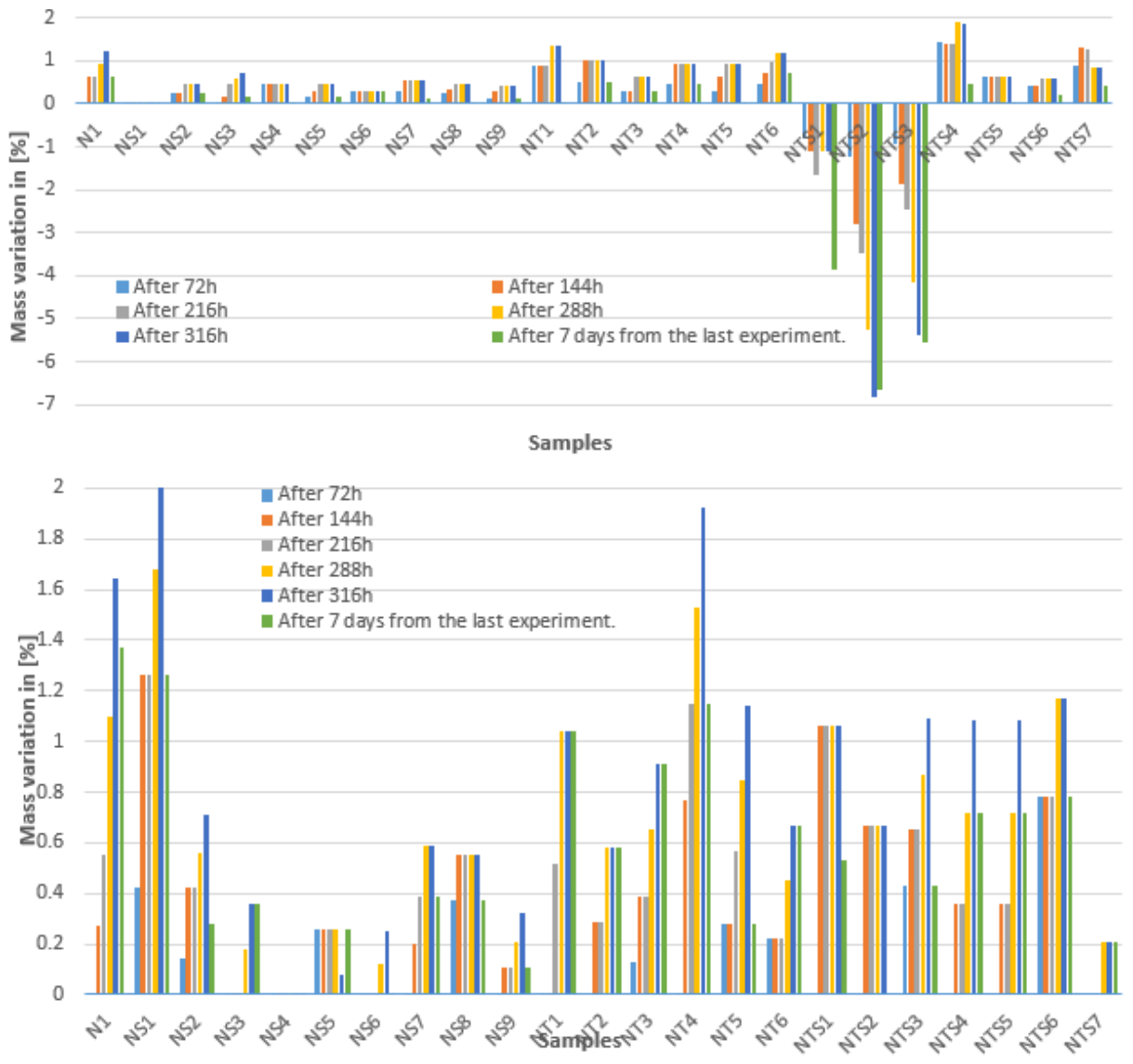

Fig. 5. The variation of mass specimens calculated in [\%] in nitric acid $10 \%$

Fig. 6. The variation of mass specimens calculated in [\%] in nitric acid $20 \%$

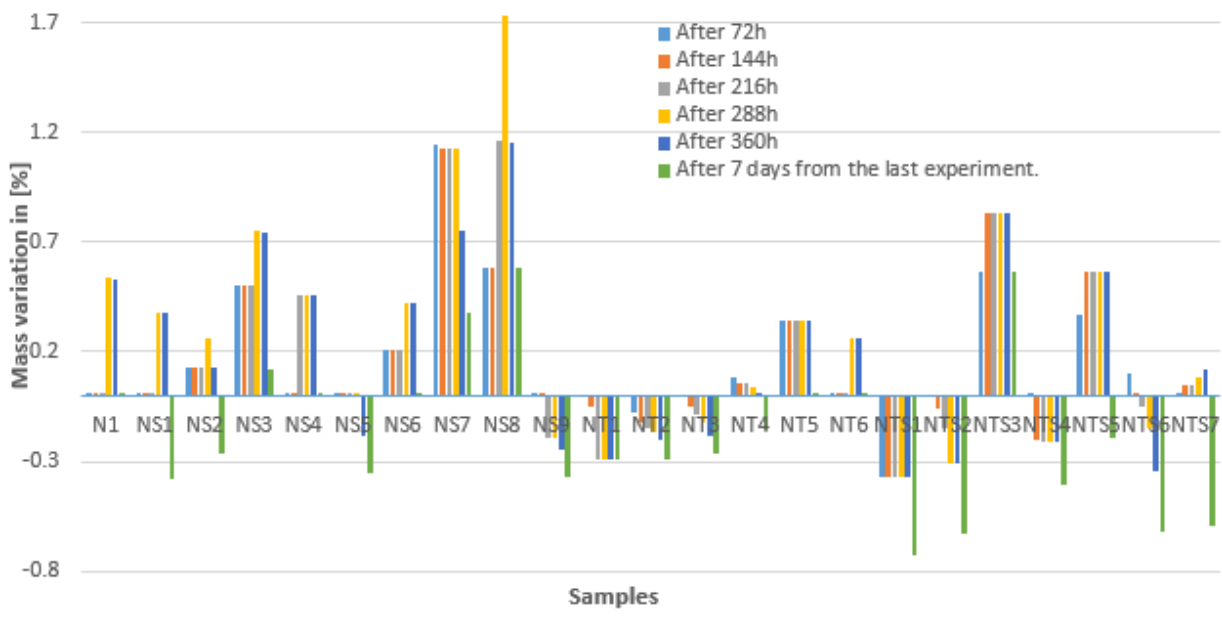

Fig. 7. The variation of mass specimens calculated in [\%] in hydrocloric acid $10 \%$,

\section{Observation}

From composite materials studied six of them it fits in group of perfectly stable material and have the stability coefficient 1 and non resistant with the stability coefficient 10 fits three materials.

After the experiment, the samples mass increased in the case of sixteen materials. The mass increase was caused by degradation of resin by the acid and fiberglass came into contact with the acid solution and was soaked.

The behavior of the composite materials in nitric acid $20 \%$, The experimental results are summarized in the diagram presented in figure 6 .

\section{Observation:}

From composite materials studied four of them it fits in group of perfectly stable material and have the stability coefficient 1 , one material fits in group of very little resistance and have the stability coefficient 8 and non resistant with the stability coefficient 10 fits three materials.
After the experiment, the samples mass increased in the case of seventeen materials. The mass increase was caused by degradation of resin by the acid and fiberglass came into contact with the acid solution and was soaked.

The behavior of the composite materials in hydrocloric acid $10 \%$.

The experimental results are summarized in the diagram presented in figure 7.

\section{Observation}

From composite materials studied five of them it fits in group of perfectly stable material and have the stability coefficient 1 , fourteen materials fits in group of very little resistanc and have the stability coefficient 8 and non resistant with the stability coefficient 10 fits four materials.

After the experiment, the samples mass increased in the case of two materials. The mass increase was caused by degradation of resin by the acid and fiberglass came into contact with the acid solution and was soaked. 


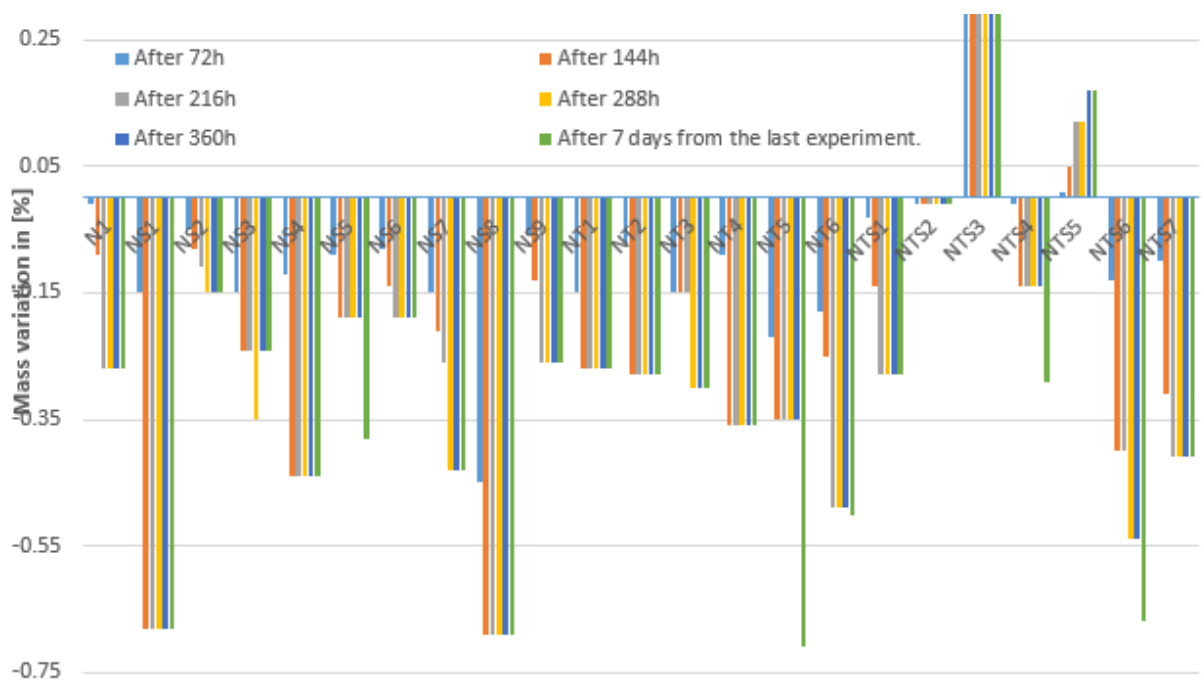

Fig. 8. The variation of mass specimens calculated in [\%] in hydrocloric acid $20 \%$

Samples

The behavior of the composite materials in hydrocloric acid $20 \%$,

The experimental results are summarized in the diagram presented in figure 8 .

\section{Observation}

From composite materials studied two of them it fits in group of perfectly stable material and have the stability coefficient 1, seventeen materials fits in group of very little resistance and have the stability coefficient 8 and non resistant with the stability coefficient 10 fits four materials.

After the experiment, the samples mass increased in the case of two materials. The mass increase was caused by degradation of resin by the acid and fiberglass came into contact with the acid solution and was soaked.

\section{Conclusions}

For materials NS5, NS6, NS7, NS8, NT1, NTS1, NTS2 and NTS3 it is not recommended the manufacture of containers for storage of sulfuric acid with a concentration of $10 \%$. From the remaining materials we can make containers for temporarystorage of these solutions (maximum six days).

If the concentration of sulfuric acid is increasing to $20 \%$ are recommended only materials NS1, NS2, NS4, NS9, NT4, NT5, NTS2, NTS5 and they only for temporary storage (maximum 3 days).

The NTS1, NTS2, NTS3 materials are not recommended for the manufacture of containers to storage the nitric acid (concentration of 10 or $20 \%$ ) and the restonly for temporary storage (maximum 3 days).

Manufacturing containers from all these composite materials is not recommended for long-term storage or temporarily in case of hydrochloric acid solutions.

Acknowledgements: This paper is supported by the Sectoral Operational Programme Human Resources Development (SOP HRD), financed from the European Social Fund and by the Romanian Government under the project number POSDRU/89/1.5/S/59323 and we hereby aknowledge the structural founds project $P R O-D D$ (POSCCE, 0.2.2.1., ID 123, SMIS 2637, ctr. No 11/2009) for providing the infrastructure used in this work.

\section{References}

1. THOMASON, J. L. The interface region in glass fiber-reinforced epoxy resin composites: 1 . Sample preparation, void content and interfacial strength.Composites 26.7 (1995),p 467-475.

2. THOMASON, J. L. The interface region in glass fiber-reinforced epoxy resin composites: 2 . Water absorption, voids and the interface. Composites 26.7 (1995), p. 477-485.

3. OLMOS, D., LOPEZ-MORON R., GONZALEZ-BENITO J. . The nature of the glass fiber surface and its effect in the water absorption of glass fiber/epoxy composites. The use of fluorescence to obtain information at the interface.Composites science and technology 66.15 (2006),p. 2758-2768.

4. DHAKAL, H. N., ZHANG Z. Y., RICHARDSON M. O. W.. "Effect of water absorption on the mechanical properties of hemp fiber reinforced unsaturated polyester composites. Composites science and technology 67.7 (2007).p. 1674-1683.

5. PIHTILI, HASIM, NIHAT TOSUN. Investigation of the wear behavior of a glass-fiber-reinforced composite and plain polyester resin. Composites Science and Technology 62.3 (2002), p. 367-370. 6. RAY, B. C. Temperature effect during humid ageing on interfaces of glass and carbon fibers reinforced epoxy composites. Journal of Colloid and Interface Science 298.1 (2006), p.111-117.

7. POP, M.A, CONSTANTINESCU, AL.Obtaining technology for thinwall patterns manufacturing used in foundry and their physicmechanical properties, Metalurgia International, vol. XVI, no. 5, (2011), p. $93-96$

8. POP M.A, MOTOC D.A.,CONSTANTINESCU AL., GEAMAN V., DERCZENI R.AL. - CTE assessment of various glass fiber reinforced polymer composite architectures, Metalurgia International, Special Issue 5 (2013), p. 131-134, ISSN: 1582-2214, 2011.

9. COTERLICI, R. F., GEAMAN, V., POP, M. A., BEDO, T., RADOMIR, I., CHIVU,O.R., FLOREA, B., SEMENESCU, A., Rev. Chim.(Bucharest), 67, no. 10, 2016,p. 2049

10. GEAMAN, V., POP, M.A., RADOMIR, I.,BEDO, FLOREA, T.B., SEMENESCU, A., CHIVU, O.R., PASARE, M., GLIGOR, A. M., Rev. Chim.(Bucharest), 67, no. 11, 2016, p. 2207

11.*** http://ro.scribd.com/doc/81557027/L3-Coroziunea-Viteza-deCoroziune (Accesed 04.12.2015)

Manuscript received: 21.02 .2017 